\title{
Analysis of New Media Empowerment --a Case Study of "EPB Swimming in the Water"
}

\author{
Mengyu Li \\ Henan University of Animal Husbandry and Economy, Zhengzhou, Henan, 450000
}

Keywords: new media, empowerment, network politics, discourse power

\begin{abstract}
At a crucial period of social transformation, China's social system has been further improved and citizen awareness has been continuously raised. The phenomenon of new media empowerment in the form of Internet politics and online rights protections continues to emerge. The theory of media empiricism originated from the West and the research on the empowerment of new media also continued to heat up in the industry. With the invitation of the netizen "Environmental Protection Bureau launching" incident, this paper analyzes the new breakthrough of media empowerment in the context of new media: the fight for discourse right and the network virtual society. After the dissemination of new media, social events have changed the public's perception of society, and the formation of topics, discussions and collective protests will be the development trend of new media empowerment.
\end{abstract}

\section{Introduction}

In the news reports and Internet search, environmental protection bureau chiefs around the "busy", on the one hand tired to deal with higher political performance inspection, but on the other hand was netizens "high reward swimming." Environmental protection has once again become a hot topic in the community. How to ensure that "green GDP" is not only a problem to be solved by the Environmental Protection Bureau but also relates to the immediate interests of every citizen. They use the Internet and mobile phones to voice their voices in social media. Concerned about environmental protection, build a beautiful home. This is the result of the development of civil society and an important manifestation of the power of new media. Citizens are aware that the use of new media to safeguard their rights and fight for expression of discourse power makes the form of new media empowerment rich and varied. This is also an important symbol of social progress toward civilization.

\section{The definition of new media and new media empowerment}

Although the term "new media" is no longer fresh, what is "new media"? Neither experts nor journalists can reach a consensus. There are three kinds of domestic comparison of authority: the first one is "digital media"; the second one is "self media" and the third one is "relative media". Foreign research on new media is also more mature earlier, the United States, "Connection" magazine on the definition of new media is "all for everyone's communication"; "new media is to provide the public at the same time personalized content media, is Communicators, and receivers converge on a peer-to-peer communicator, while innumerable communicators can simultaneously communicate individually and individually. "The statement was made by Wencross, a veteran US media analyst. To sum up, the author thinks that the so-called new media is the media form that is developed with the support of high technologies such as the Internet and computers. Its essence is the medium of highly interactivity and multi-compound information.

"Empowerment" originated from the theory of human resources: the so-called empowerment is to improve employee-related work discretion, so can increase productivity. Empowerment is a participatory process that grants or transfers control of decision-making responsibilities and resources to those who are about to benefit. In fact, empowerment means that empowered people have a greater degree of independence and autonomy. Western research is more mature and 
comprehensive on media empowerment: in Fleury and Alinski's writings, empowerment was first seen as a process of communication, all of whom considered the communication process to promote empowerment. Rogers and Singh advocate the fundamental empowerment as a process of communication that arises from the interaction of many individuals within a small group. Of course, some scholars have analyzed some cases of participatory development dissemination and pointed out that the empowerment process essentially includes the spread of dialogue. By influencing people, especially their peers, people have an influence on the realization of the goals they are anxious to achieve confidence.

Media empowerment is sometimes personal, sometimes manifested as a community or group (such as a group, a cluster, or an organization). Further, media empowerment is a multi-level structure that affects each other at every level. On the individual level, it refers to self-empowerment or psychological empowerment. It integrates the individual's cognition of the control over the media content, the proactive approach of public affairs through the media and the critical understanding of the social and political environment awareness. In the context of communication, the social dimension of empowerment should refer to changes in the pattern of distribution of media resources and public discourse. In summary, media communication is a catalyst for empowerment, and the empowerment process can be said to be a participatory process of communication. The "media empowerment" takes the participation of all media as a form of communication, focuses on the empowerment of citizens, and aims at social mobility.

Ding Wei from Shenzhen University is an earlier scholar studying the empowerment of the media in China. She proposed: On the one hand, it is necessary to develop a set of analytical framework and variables suitable for new modes of participation, social networks and interactive forms in the new media environment, Empowerment is reduced to a trendy but marginalized neglect; on the other hand, optimistic assumptions about the "potential for social media and empowerment" by the new media proposed by Western scholars also need to be made Further discussion. In other words, new media empowerment is an emerging phenomenon in media and social development. It can neither pessimistically negate its growth space and its utility to society, nor can it optimistically exaggerate its promoting function in a particular social system or social environment. However, judging from the status of the development of new media in our country at present, the new media makes it possible for all groups (especially the populist class) to gain power and capability in all aspects of discourse, economy, culture, politics and social capital.

The spread of new media focuses on the freedom of individual choice, which is a "double-edged sword." First, individuals regained their right to speak freely. Mainly manifested in the role of information disseminators and recipients transposition, as well as changes in the pattern with the traditional media, and ultimately the formation of a new media under the influence of civil society. Second, the influence on the order of communication is even more obvious. The new media has played down the original media landscape, changed the status of the traditional media in grasping the right to communication, and won the "one hundred schools of thought" for the right to speak. Creating a new media environment centered on new media aims to share the unique characteristics of new media empowerment. With the participation of the public, the discussion of the topics, the influence of the media and the network politics as the representatives, the continuous improvement of civic awareness enables the new media to create a more free communication order and a democratic and equal social order.

\section{3. "Environmental Protection Agency Launching" incident}

"Environmental Protection Bureau launching" incident originated in Hangzhou Mao Yuanchang chairman Jin Zengmin, he posted a microblogging: "This is the Ruian City, Zhejiang Province Xianxian Street rubber shoe factory base (the largest number of) industrial pollution, very serious, direct drainage row into the rivers, for attention ... ... Cancer patients from absurd, abercrombie, the EPA director dare to swim in the river for 20 minutes I took out 200,000." Also attached to the four rivers contaminated photos, shocking. The "high price" invited the director of Environmental Protection to swim in the river and was initially forwarded and commented as "jokes" by netizens. 
It was merely a "speculation" on the Internet and a joke and a fuss over the current EPA's inaction. But soon, users follow the example of Jin Zengmin, also made microblogging or launched in the forum "to encourage environmental protection director swim into the water," swept the network for a time.

Netizens in Shenzhen, Dongguan, Wenzhou and other places also "pay for their own money" invites environmental directors from all over the world to show their glitches. However, the "hottest" EPBs have all turned into "silent people." Both the official response and the director personally "Invitations" ignored. Soon, newspapers, radio and television media reporters interviewed Bao Anming, the chief environmental officer at Shui On, saying: "This duty is not with us and we must pay attention. Then we will remind the water conservancy department that we To learn the last resort, do not wait for everything to come out and do it again. "After the news release, Internet users set off a new round of" network accountability. "Who should be responsible for river pollution?

Another news report - Su Zhongjie, Census and Environmental Protection Bureau of Zhejiang Province, was forced to respond to the "invitation" to bring the incident to a climax. In May 2013, a police officer at Cangnan County, Zhang Guangcong, rescued a girl under the river and led to a hospitalization of his lung infection. Su Zhongjie as a leader went to visit him. In this awkward condolences, Zhang Guangcong made a heartfelt remark to the Environmental Protection Bureau: The best comfort is to govern the river well. After experiencing the reward swimming and awkward condolences, Su Zhongjie told reporters that whatever he could do was to send supervisors to Jinxiang River for investigation within the scope of its limited functions.

Environmental Protection Bureau chiefs in Shenzhen, Wenzhou and other places changed their attitude of "turning a deaf earnest". They held a press conference and interviewed by the media to face the invitation to "swim down the river" with a more positive attitude. At the same time, various departments also took the initiative with the environmental protection department, determined to control pollution. Internet users posted the EPA "response posts", causing a new round of forwarding and hot. At this point, "EPB swim" incident ended.

\section{The new media empowerment in the context of discourse and expression}

On the "Environmental Protection Agency to swim" incident, Jinzeng Min and others on the microblogging release news, causing netizens onlookers. After the fission network spread, the network events are gradually formed. Soon the media and public in the real society are involved, the "network society" and the "real society" form a butt connection, and a "media wave" is set off on the network to promote the incident. People respond positively, so as to get the "determination to control pollution and make the living environment become better and better".

Foucault, the French philosopher, put forward "the theory of discourse right" earliest: Discourse is a kind of power relationship, a manifestation of power, a tool of knowledge transmission and power control. It means who has the right to speak and who has no right to speak. The emergence of new media, so that discourse becomes fragmented, can not be the original media structure under the influence of the right to speak. But precisely because the users of new media act as both communicators and recipients, the dissemination of information is quicker. However, because of the common interest needs, decentralized discourse power forms a common discourse power of the collective group, which is not a mere superposition of individual discourses but an uncontrollable utility by utilizing the propagation characteristics of new media.

In the "EPB's swimming in the water" incident, Kim Min-jin first proposed this invitation for the purpose of improving itself and the living environment of local residents. Netizens from Shenzhen, Wenzhou, Dongguan and Heilongjiang also made invitations in the hope of receiving the attention and reply from the Environmental Protection Agency and jointly improving the environment and building a beautiful homeland. The formation of dispersed discourse from the collection, through the spread of the network formed a hot event, the reality of the media, the public's argue and vocal opposition, so that this incident as a public event.

In most cases, the "right" in new media empowerment is understood as "right". However, in 
empowerment theory, "right" means "power." As far as the right to speak is concerned, discourse is not merely a skill, but also means that there is a right, that is, the right to use one's own power through language. In the new media empowerment, the right to speak has the dual attributes of power and right.

Netizens invited "Secretary swim under the river," is a manifestation of civil rights, but also a political participation. The "invitation" is for the sake of safeguarding one's own interests and therefore has another meaning of "discourse right". Of course, there are different "voices" among different strata in the "EPB's swimming into the water" incident: For example, the elite represented by Jin Zengmin is to protect the living environment of local residents, including him. On the one hand, On the other hand, he is Mao Yuanchang's chairman and belongs to the elite class. The incident spreads advertising for his company for free. The civilian class, they are just the general public, do not have the authority and charisma of "opinion leaders," but they are the backbone for promoting the development of the incident is "forced" to voice its voices in an attempt to secure the interests of their own living environment. Most of them do not have the concept of power. They think that the government's decision-making is not disturbed by public opinions, but spontaneously involved in the "EPB's swimming and swimming" incident, and they are satisfactorily resolved through the incident. They are also aware of the right to speak Importance, which is the new achievements of the new media empowerment; the last is the strong class, represented by the government departments, although the official microblogging, websites are also actively establishing, or even set the main public issues, but in the incident, the EPA As the representative of the government departments, has chosen a silent response, not only detrimental to the government's image, but also affected the resolution of the incident.

Who is empowering new media?

The study of western empowerment is mainly aimed at subordinates, minorities and marginalized groups in the enterprise and is regarded as the "vulnerable group" in our country. This group is not very much in line with the participants of the "EPA's water and swimming" incident. So what exactly "right" where? Yu Jianrong once said: In the Internet age will be subject matter set into a public event, the agenda set mainly to protest and empowerment. In general, opinion leaders first protest, express their dissatisfaction with the heart, and then empowerment, giving the people certain rights through network issues. There is another argument that self-empowerment of online groups, through new media expression to highlight the influence. In the era of new media, opinion leaders are one of the participants. They can not "empower" others. Network events themselves are formed through multiple communications and commentary by users. Therefore, they are not empowered by participants. Therefore, users of new media spontaneously use the new media to publish and comment on information, which is the origin of network events and an expression of self-empowerment. The progress of society and the awakening of citizens themselves are the soil for the growth of the new media's empowerment. At the same time, the new media empowerment also promoted the improvement of the awareness of the rights represented by the progress of society and the right of citizens to speak.

\section{Conclusions}

In China's media landscape, using new media to fight for discourse, asking political parties over the Internet, monitoring public opinion, etc. is a manifestation of the new media's empowerment and also a positive effect. Taking the case of "EPB swimming in the water" as an example, netizens expressed their opinions in a rational and orderly manner and conducted "ridicule" "attacks" on the inaction of the EPA director, which promoted the high degree of concern of the relevant departments. After repeated "propaganda" "And" invitation ", the EPA finally made a positive response, saying that it will fully control pollution and also provide us a beautiful environment. This is the fight for and safeguarding civil rights and has achieved good results. It also confirms the purpose of new media empowerment: to influence social mobility. However, the development of new media in China has just started. Citizenship is also at the enlightenment stage. How to play a greater role in empowering new media so that more people can correctly use new media to spread 
positive energy while avoiding "cyber-violence" and "network rumors "And other negative effects, this is a new issue to be faced by the people.

\section{References}

[1] Ding Wei. New media and empowerment: a practical social research [J]. International Press .2009 (10), 76-81.

[2] Vin Crosbie. What is New Media? [EB / OL]. websit: http://rebuildingmedia.corante.com/, June 3, 2010.

[3] Frielaanl. Communication, Community, and Democracy: Toward a Theory of the Communicatively Integrated Community. Communication Research [J]. 2001 (28), 358-391.

[4] Rogerse, Singhala. Powerment and Communication: Lessons Learned from Organizing for Social Change [M]. Lawrence Erlbaum Associates, 2003, 67-85.

[5] Zimmer Manma. Psychological Empowerment: Issues and Illustrations. American Journal of Community Psychology [J]. 1995 (23), 581-599.

[6] Ma Liming understand the public "reward swimming" behind the expectations [N]. Shenzhen Special Zone Daily. February 26, 2013 No. A02.

[7] Li Ye. Embarrassed condolence [N]. Liberation Daily. June 20, 2013 edition 005.

[8] Qian Yuelin. New media and emerging media [J]. Radio and Television Technology. 2009 (8), 46-48.

[9] Wang Weiyan. The Deconstruction of Citizen News in the Context of New Media [J]. Journal Youth. 2013 (21), 87-88.

[10] [France] Althusser. Chen Yue translation. Philosophy and Politics [M]. Changchun: Jilin People's Publishing House, 2004, 157.

[11] Liang Yi, Liu Hua. Research on Internet Empowerment: Processes and Problems [J]. Southeastwards.2013 (4), 14-17.

[12] China Broadcasting Network. Ryan EPA was invited to waste water river swim 20 minutes said the responsibility is not EPA [N]. China Broadcasting Network. Http: //china.cnr.cn/xwwgf/201302/t20130218_511980646.shtml, 2013 February 18. 